\title{
Altered Behavioral Responses to Noxious Stimuli and Fear in Glutamate Receptor 5 (GluR5)- or GluR6-Deficient Mice
}

\author{
Shanelle Ko, ${ }^{\star}$ Ming-Gao Zhao, ${ }^{*}$ Hiroki Toyoda, ${ }^{*}$ Chang-Shen Qiu, and Min Zhuo \\ Department of Physiology, Faculty of Medicine, and Centre for the Study of Pain, University of Toronto, Toronto, Ontario M5S 1A8, Canada
}

\begin{abstract}
Different kainate receptor (KAR) subtypes contribute to the regulation of both excitatory and inhibitory transmission. However, no study has reported a role for KAR subtypes in behavioral responses to persistent pain and fear memory. Here we show that responses to capsaicin or inflammatory pain were significantly reduced in mice lacking glutamate receptor 5 (GluR5) but not GluR6 subunits. In classic fear-memory tests, mice lacking GluR6 but not GluR5 showed a significant reduction in fear memory when measured 3, 7, or 14 d after training. Additionally, synaptic potentiation was significantly reduced in the lateral amygdala of GluR6 but not GluR5 knock-out mice. Our findings provide evidence that distinct KAR subtypes contribute to chemical/inflammatory pain and fear memory. Selectively targeting different KAR subtypes may provide a useful strategy for treating persistent pain and fear-related mental disorders.
\end{abstract}

Key words: kainate receptor; fear memory; inflammatory pain; capsaicin; complete Freund's adjuvant; knock-out mice

\section{Introduction}

Kainate receptors (KARs) are composed of five different subunits (Hollmann and Heinemann, 1994). These include glutamate receptor 5 (GluR5), GluR6, and GluR7 subunits, which form functional homomeric receptors, and KA1 and KA2, which combine in heteromeric receptors but do not form functional ion channels on their own. In the periphery and spinal cord, KARs play an important role in sensory transmission. KARs are located on sensory afferent fibers and dorsal root ganglion (DRG) cells (Partin et al., 1993; Tolle et al., 1993; Procter et al., 1998; Hwang et al., 2001; Kerchner et al., 2001b, 2002). In the spinal cord, they are located on the postsynaptic membrane of dorsal horn neurons and contribute to synaptic responses to high-threshold primary afferent fiber stimulation (Li et al., 1999). KARs are also present presynaptically on the primary afferent fibers themselves (Davies et al., 1979; Huettner, 1990), where they can regulate glutamate release in the spinal cord (Kerchner et al., 2001a). Furthermore, presynaptic KARs biphasically regulate inhibitory transmission in the spinal dorsal horn (Kerchner and Zhuo, 2002). The deletion of GluR5 abolished KAR function in DRG neurons (Kerchner et al., 2002). However, glutamate-mediated sensory synaptic transmission is normal in spinal cord slices of GluR5 and GluR6 knock-out mice (Youn and Randic, 2004). Behavioral responses to both formalin and complete Freund's adjuvant (CFA) are reduced when

\footnotetext{
Received May 27, 2004; revised Nov. 23, 2004; accepted Dec. 13, 2004.

We are thankful for funding supports from the EJLB-Canadian Institutes of Health Research (CIHR) Michael Smith Chair in Neurosciences and Mental Health in Canada, the Canadian Research Chair, CIHR, and National Institutes of Health-National Institute of Neurological Disorders and Stroke Grant 42722. M.-G.Z. is supported by a postdoctoral fellowship from the Fragile X Research Foundation of Canada. We thank Dr. S. F. Heinemann for providing GluR5 and GluR6 knock-out mice and Dr. J Huettner for providing help with breeding and genotyping.

*S.K., M.-G.Z., and H.T. contributed equally to this work.

Correspondence should be addressed to Dr. Min Zhuo, Department of Physiology, University of Toronto, 1 King's College Circle, Medical Sciences Building, Room 3342, Toronto, Ontario M5S 1A8, Canada. E-mail: min.zhuo@utoronto.ca.

DOI:10.1523/JNEUROSCI.4059-04.2005

Copyright $\odot 2005$ Society for Neuroscience $\quad$ 0270-6474/05/250977-08\$15.00/0
}

animals are treated with the selective GluR5 receptor antagonist (3S,4aR,6S,8aR)-6-(4-carboxyphenyl)methyl-1,2,3,4,4a,5,6,7,8,8adecahydroisoquinoline-3-carboxylic acid (LY382884) (Simmons et al., 1998; Guo et al., 2002), indicating a role for GluR5 in pain transmission. These findings suggest that GluR5 is essential for KARmediated responses in DRG cells and for presynaptic regulation in the spinal dorsal horn.

KARs are also distributed in higher brain structures, such as the amygdala and related cortical areas (Hollmann and Heinemann, 1994; Li et al., 2001). In the hippocampus, KARs contribute to presynaptic regulation and postsynaptic responses to repetitive stimulation (Frerking and Nicoll, 2000; Kullmann, 2001; Huettner et al., 2002; Lerma, 2003). GluR5-containing KARs in the amygdala contribute to heterosynaptic facilitation induced by prolonged low-frequency stimulation (Li et al., 2001). The role of the KAR subtypes GluR5 and GluR6 in fear memory has yet to be elucidated. Additionally, although studies have shown that GluR5 antagonists can attenuate responses to persistent pain, no study has examined nociceptive responses in both GluR5 and GluR6 knock-out mice. In the present study, we used knock-out mice to explore the contribution of GluR5 and GluR6 receptors to sensory responses, fear memory, and learning-related synaptic potentiation in the amygdala. Several tests for acute thermal sensitivity and chemically induced persistent pain were used to elucidate selective roles for both KAR subtypes in nociceptive responses. It is important to understand how different receptor subtypes contribute to pain and fear memory, because such an understanding may lead to the development of more efficacious treatments for chronic pain and memory loss.

\section{Materials and Methods}

Mice. Adult male mice ( $8-12$ weeks of age) were used for all experiments. GluR5 and GluR6 knock-out mice were gifts from Dr. Stephen F. Heinemann (The Salk Institute, San Diego, CA) (Mulle et al., 1998, 2000). Mice were housed on a $12 \mathrm{~h}$ light/dark cycle with ad libitum access to food and water. GluR5 and GluR6 knock-out mice were maintained on a mixed 
$129 \mathrm{~Sv} \times$ C57BL/6 background, and 129Sv/C57BL/6 mice from Taconic (Germantown, NY) were used as controls. Additional experiments were performed on GluR5 and GluR6 wild-type littermates, and no significant difference was found when compared with 129Sv/C57BL/6 mice from Taconic. The Animal Care and Use Committee at the University of Toronto approved all mouse protocols. Because GluR5 and GluR6 knockout mice are visually indistinguishable, all experiments were performed blind to the genotype.

Sensory stimuli and inflammation. The tail-flick reflex was evoked by focused, radiant heat applied to the underside of the tail. In the hot-plate test, mice were placed on a thermally controlled metal plate (Columbia Instruments, Columbus, $\mathrm{OH}$ ). The time between placement on the plate and licking or lifting of a hindpaw was measured. Mice were removed after a response, and the cutoff was $30 \mathrm{~s}$. Mechanical withdrawal thresholds were assessed with von Frey filaments (Stoelting, Wood Dale, IL) modified so that the filament extended parallel to the rod. The mean response was calculated as the average of five to six measurements performed at 10 min intervals.

Capsaicin [ $1 \mu \mathrm{g}$ per $10 \mu \mathrm{l}$ in 7.5\% DMSO/saline (10 $\mu \mathrm{l})$; Sigma, St. Louis, MO] was injected into the dorsal skin of one hindpaw. Licking of the injected hindpaw was recorded during every 5 min interval for a total of $30 \mathrm{~min}$. For inflammatory pain, formalin $(5 \%, 10 \mu \mathrm{l})$ was injected into the dorsal side of a hindpaw. The total time spent licking or biting the injected hindpaw was recorded over the course of $2 \mathrm{~h}$ in $5 \mathrm{~min}$ intervals. Three phases of formalin licking were recorded, because previous studies have shown that behavioral differences may occur selectively in the third phase (Wei et al., 2001). CFA (50\% in saline, $10 \mu \mathrm{l}$; Sigma) was injected into the dorsal surface of the left hindpaw under halothane anesthesia. After 1 or $3 \mathrm{~d}$, animals were placed in individual plastic boxes and allowed to adjust to the environment for $1 \mathrm{~h}$. Using the up-down paradigm (Chaplan et al., 1994), mechanical sensitivity was assessed with von Frey filaments (Stoelting) modified as described above. Based on preliminary experiments that characterized the threshold stimulus in untreated animals, the innocuous $0.4 \mathrm{mN}$ (\#2.44) filament, representing $50 \%$ of the threshold force, was used to detect mechanical allodynia. The filament was applied to the point of bending six times each to the dorsal surfaces of the left and right hindpaws. Positive responses included prolonged hindpaw withdrawal followed by licking or scratching. The percentage response frequency of withdrawal was expressed as follows: (number of positive responses) $/ 6 \times 100$ per hindpaw. Hindpaw edema was evaluated with a vernier caliper (Bel-Art Products, Pequannock, NJ) $3 \mathrm{~d}$ after CFA injection.

Fear memory. Fear conditioning was performed in an isolated shock chamber (Med Associates, St. Albans, VT). An experimenter blind to the genotype manually scored freezing responses (total immobility aside from respiration) every $10 \mathrm{~s}$. The conditioned stimulus (CS) was an $85 \mathrm{~dB}$ sound at $2800 \mathrm{~Hz}$, and the unconditioned stimulus (US) was a continuous scrambled footshock at $0.75 \mathrm{~mA}$. After $2 \mathrm{~min}$ of habituation, animals received the CS/US pairing [a 30 s tone (CS) and a $2 \mathrm{~s} \mathrm{shock} \mathrm{(US)} \mathrm{starting}$ at $28 \mathrm{~s}$; three shock-tone pairings were delivered at 30 s intervals], and the mice remained in the chamber for an additional $30 \mathrm{~s}$ to measure immediate freezing. At $1 \mathrm{~h}$ and 1, 3, 7, and $14 \mathrm{~d}$ after training, each mouse was placed back into the shock chamber and the freezing response was recorded for $3 \mathrm{~min}$ (contextual conditioning). Subsequently, the mice were placed into a novel chamber and monitored for $3 \mathrm{~min}$ before the onset of a tone identical to the CS, which was delivered for $3 \mathrm{~min}$, and freezing responses were recorded (auditory conditioning).

Slice electrophysiology. Animals were anesthetized with halothane. Transverse slices $(400 \mu \mathrm{M})$ of the amygdala and auditory cortex were rapidly prepared using a vibratome (Vibratome Series 1000; Technical Products International, St. Louis, MO) and maintained in an interface chamber at $30^{\circ} \mathrm{C}$, where they were subfused with artificial CSF (ACSF) consisting of (in mM): $124 \mathrm{NaCl}, 4.4 \mathrm{KCl}, 2.0 \mathrm{CaCl}_{2}, 1.0 \mathrm{MgSO}_{4}, 25$ $\mathrm{NaHCO}_{3}, 1.0 \mathrm{NaH}_{2} \mathrm{PO}_{4}$, and 10 glucose, bubbled with $95 \% \mathrm{O}_{2}$ and $5 \%$ $\mathrm{CO}_{2}$. Slices were kept in the recording chamber for at least $2 \mathrm{~h}$ before the start of experiments (Wei et al., 2002). In amygdala slices, a bipolar tungsten stimulating electrode (Micro Probe, Potomac, MD) was placed in the ventral striatum, and an extracellular recording electrode (3-12 $\mathrm{M} \Omega$, filled with ACSF) was placed in the lateral amygdala (LA). In audi- tory cortical slices, a bipolar tungsten stimulating electrode was placed in layer $\mathrm{V}$, and extracellular field potentials were recorded using a glass microelectrode placed in layer II/III. Synaptic responses were elicited every 50 s by electrical stimulation ( $200 \mu$ s duration). After obtaining stable recordings for at least 15-20 min, five trains of theta burst stimulation (TBS), which consisted of five bursts (four pulses at $100 \mathrm{~Hz}$ ) of stimuli delivered every $200 \mathrm{~ms}$ at the same intensity, were applied.

Whole-cell patch-clamp recordings. Transverse slices $(300 \mu \mathrm{M})$ of the amygdala were transferred to a room-temperature submerged recovery chamber with oxygenated $\left(95 \% \mathrm{O}_{2}\right.$ and $\left.5 \% \mathrm{CO}_{2}\right)$ ACSF solution as described above. After a $1 \mathrm{~h}$ recovery, slices were placed in a recording chamber on the stage of an Axioskop 2FS microscope (Zeiss, Thornwood, NY) equipped with infrared differential interference contrast optics for visualized whole-cell patch-clamp recordings. EPSCs were recorded from cells in the lateral amygdala with an Axon 200B amplifier (Axon Instruments, Union City, CA). Electrical stimulations (200 $\mu \mathrm{s}$ duration) were delivered by a bipolar tungsten stimulating electrode placed in the internal capsule (thalamic inputs) (Tsvetkov et al., 2004). EPSCs were induced by repetitive stimulations at $0.02-0.05 \mathrm{~Hz}$, and neurons were voltage clamped at $-70 \mathrm{mV}$. In all experiments, the stimulus intensity was adjusted to produce synaptic responses with an amplitude of 70-100 pA. In long-term potentiation (LTP) experiments, the recording pipettes (3-5 M $\Omega$ ) were filled with solution containing (in mM): 145 K-gluconate, $5.0 \mathrm{NaCl}, 1.0 \mathrm{MgCl}_{2}$, 0.2 EGTA, 10 HEPES, 2.0 Mg-ATP, and $0.1 \mathrm{Na}_{3}$-GTP, adjusted to a pH of 7.2 with $\mathrm{KOH}(280-300$ mOsm). Picrotoxin $(100 \mu \mathrm{M})$ was always present in the perfusion solution (ACSF) to block $\mathrm{GABA}_{\mathrm{A}}$ receptor-mediated inhibitory synaptic currents. After obtaining a stable EPSC for at least $10 \mathrm{~min}$, LTP was induced by 80 pulses at $2 \mathrm{~Hz}$ paired with postsynaptic depolarization at $+30 \mathrm{mV}$ (Tsvetkov et al., 2004). AMPA receptor-mediated components of EPSCs were pharmacologically isolated in ACSF containing AP-5 (50 $\mu \mathrm{M})$ and picrotoxin $(100 \mu \mathrm{M})$. To detect KAR-mediated EPSCs, ( \pm )-4-(4aminophenyl)-1,2-dihydro-1-methyl-2-propylcarbamoyl-6,7-

methylenedioxyphthalazine (SYM2206; $100 \mu \mathrm{M})$ and CNQX $(20 \mu \mathrm{M})$ were sequentially applied through bath solution. The patch electrodes contained (in mM): 120 cesium gluconate, $5.0 \mathrm{NaCl}, 1.0 \mathrm{MgCl}_{2}, 0.5$ EGTA, 2.0 MgATP, $0.1 \mathrm{Na}_{3} \mathrm{GTP}$, 10 HEPES, and 2.0 lidocaine $N$-methyl bromide quaternary salt (QX-314), adjusted to $\mathrm{pH} 7.2$ with $\mathrm{CsOH}(280-$ $300 \mathrm{mOsm}$ ). Access resistance was 15-30 M $\Omega$ and monitored throughout the experiment. Data were discarded if access resistance changed $>15 \%$ during an experiment.

Drugs. All chemicals and drugs were obtained from Sigma, except for SYM2206 and QX-314, which were from Tocris Cookson (Ellisville, MO).

Data analysis. Results were expressed as mean \pm SEM. Statistical comparisons were performed using a one- or two-way ANOVA and the Student-Newman-Keuls test for post hoc comparisons. In all cases, $p<0.05$ was considered statistically significant.

\section{Results}

\section{Responses to noxious stimuli and inflammation}

To determine whether thermal sensitivity might be altered in GluR5 or GluR6 knock-out mice, we used the spinal tail-flick reflex and the hot-plate test. In the tail-flick test, no significant difference was found between wild-type, GluR5 knock-out, and GluR6 knock-out mice (wild-type, $n=10$; GluR5, $n=14$; GluR6, $n=8$ ) (Fig. $1 \mathrm{~A}$ ). In the hot-plate test $\left(55^{\circ} \mathrm{C}\right)$, again, no difference was found in response latencies (wild-type, $n=10$; GluR5, $n=$ 14 ; GluR6, $n=8$ ) (Fig. $1 B$ ). To detect possible changes in threshold, we set the hot-plate to a lower temperature $\left(50^{\circ} \mathrm{C}\right)$ and found no significant difference (wild-type, $n=10$; GluR5, $n=14$; GluR6, $n=8$ ) (Fig. 1B). We also measured hindpaw withdrawal thresholds to mechanical stimuli with von Frey filaments and found no significant difference among groups [wild-type, $n=6$ (mean, $1.9 \pm 0.2 \mathrm{~g}$ ); GluR5, $n=6$ (mean, $2.1 \pm 0.2 \mathrm{~g}$ ); GluR6, $n=$ 5 (mean, $1.9 \pm 0.2 \mathrm{~g}$ )] (Fig. 1C). These results indicate that GluR5 and GluR6 receptors do not contribute to acute nociceptive transmission or mechanical sensitivity. 


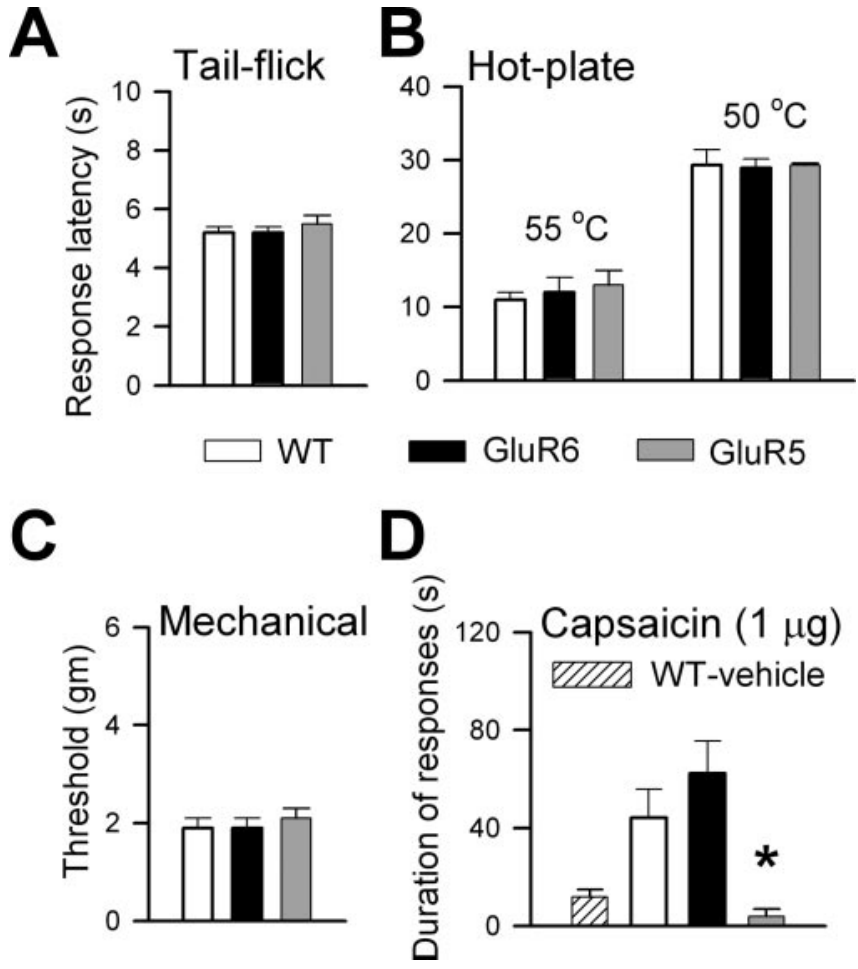

Figure 1. Acute nociception and responses to capsaicin in wild-type (WT), GluR5 knock-out, and GluR6 knock-out mice. $A, B$, Nociceptive responses in the tail-flick reflex $(A)$ and hot-plate test ( $B)$. C, Mechanical withdrawal thresholds measured using von Frey filaments. D, Behavioral responses to capsaicin (total $30 \mathrm{~min}$ ) in wild-type mice compared with GluR5 and GluR6 knockout mice and wild-type mice injected with the vehicle solution. ${ }^{*} p<0.05$, significant difference from wild-type mice treated with capsaicin.

A peripheral subcutaneous injection of capsaicin was used to evaluate the role of KARs in response to a more prolonged nociceptive stimulus (Caterina et al., 2000). After injection, wild-type mice $(n=9)($ Fig. $1 D)$ displayed licking behaviors for $30 \mathrm{~min}$. Similar responses were obtained from wild-type littermate mice ( $n=5$; mean, $64.2 \pm 19.5 \mathrm{~s}$ ). However, a significant reduction in the licking response to capsaicin was found in GluR5 knock-out mice $(n=7 ; p<0.05)$ (Fig. $1 D)$. In contrast, responses to capsaicin injection were not significantly different in GluR6 knockout mice $(n=7)$ (Fig. $1 D)$. GluR5 knock-out mice $(n=5 ; p=$ $0.46)$ and wild-type littermate mice $(n=7)$ responded similarly when injected with the vehicle solution.

A peripheral injection of formalin, a common model for tissue injury and inflammatory pain, was used to determine whether KARs play a role in behavioral responses to inflammation. Interestingly, we found a significant reduction in all three phases of the licking response in GluR5 knock-out mice $(n=7)$ (Fig. $2 A, B$ ) compared with wild-type mice $(n=10)$. As before, licking responses were normal in GluR6 knock-out mice $(n=8)$ (Fig. $2 A, B)$. The formalin licking response was also significantly reduced in GluR5 knock-out mice when compared with wild-type littermates $(n=8)(p<0.05$ for each phase).

CFA $(50 \%, 10 \mu \mathrm{l})$, a model for more prolonged inflammatory pain, was injected into the dorsum of a hindpaw in wild-type, GluR5, and GluR6 knock-out mice (Wei et al., 2001). Application of a von Frey fiber to the hindpaw elicited no response in untreated mice. However, at 1 and $3 \mathrm{~d}$ after CFA injection, mice responded to mechanical stimulation of either the same (ipsilateral) or, to a lesser extent, the contralateral hindpaw. We found that mechanical allodynia, or the display of nociceptive responses
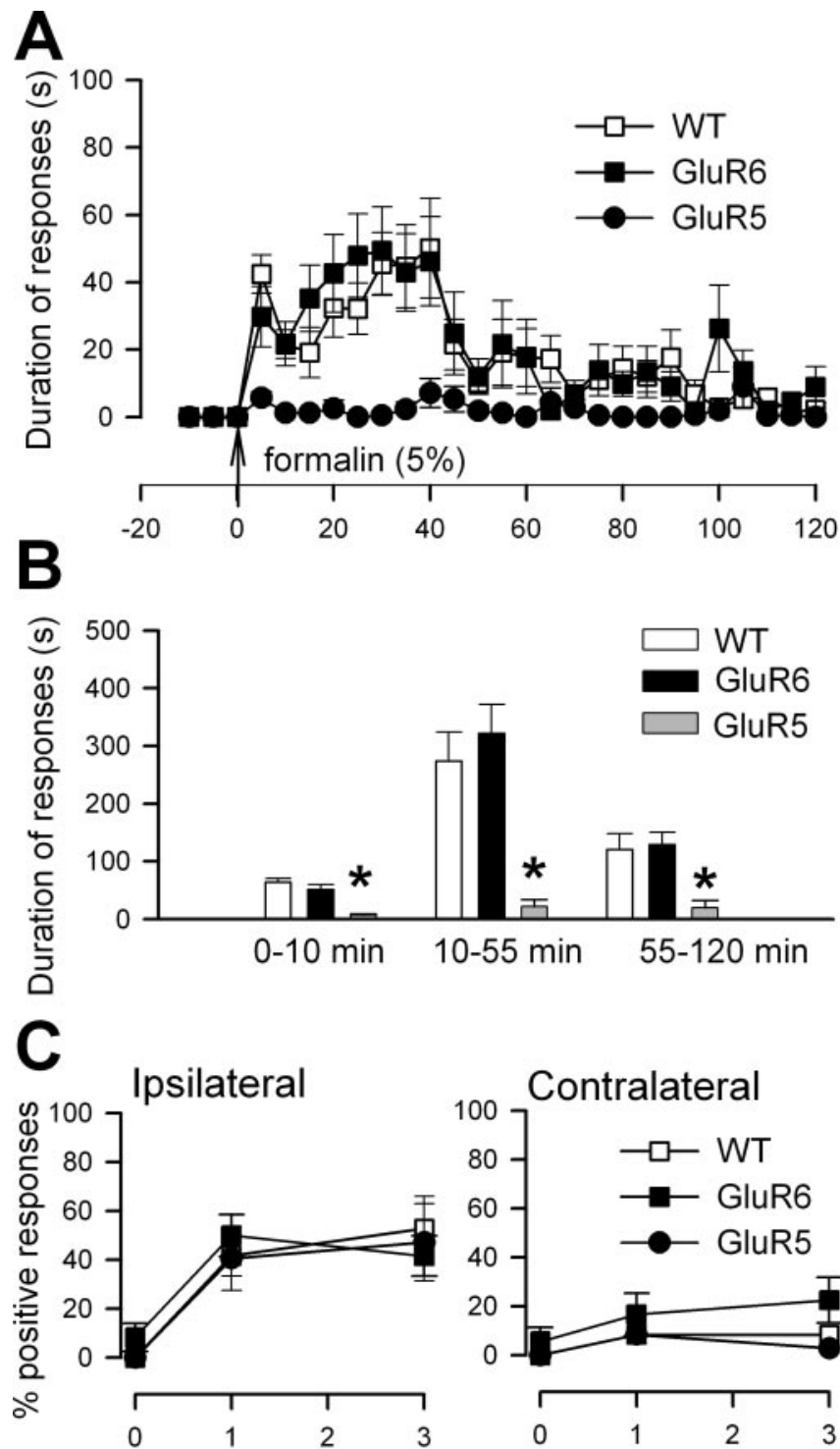

D

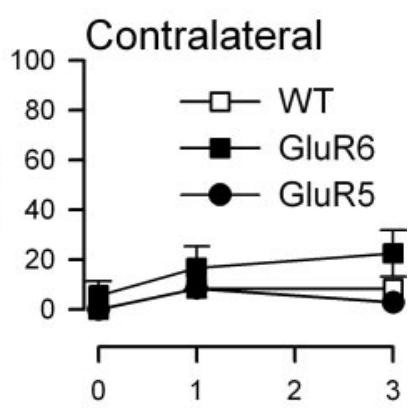

Time after CFA (days) Time after CFA (days)

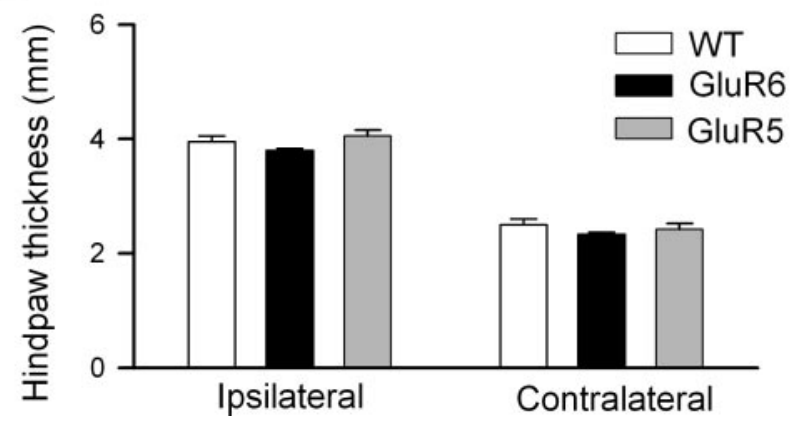

Figure 2. Reduced response to formalin in GluR5 but not GluR6 knock-out mice. A, Behavioral responses to formalin injection, plotted in 5 min intervals, in wild-type (WT) mice compared with GluR5 and GluR6 knock-out mice. B, Data from $A$ grouped into three phases. $C$, Behavioral responses after CFA injection. Data are plotted as a percentage of positive responses to stimulation of the ipsilateral or contralateral hindpaw in wild-type, GluR5 knock-out, and GluR6 knock-out mice. D, Hindpaw edema was measured with a fine caliper in wild-type, GluR5 knock-out, and GluR6 knock-out mice $3 \mathrm{~d}$ after CFA injection. ${ }^{*} p<0.05$, significant difference from wild-type mice injected with formalin. 

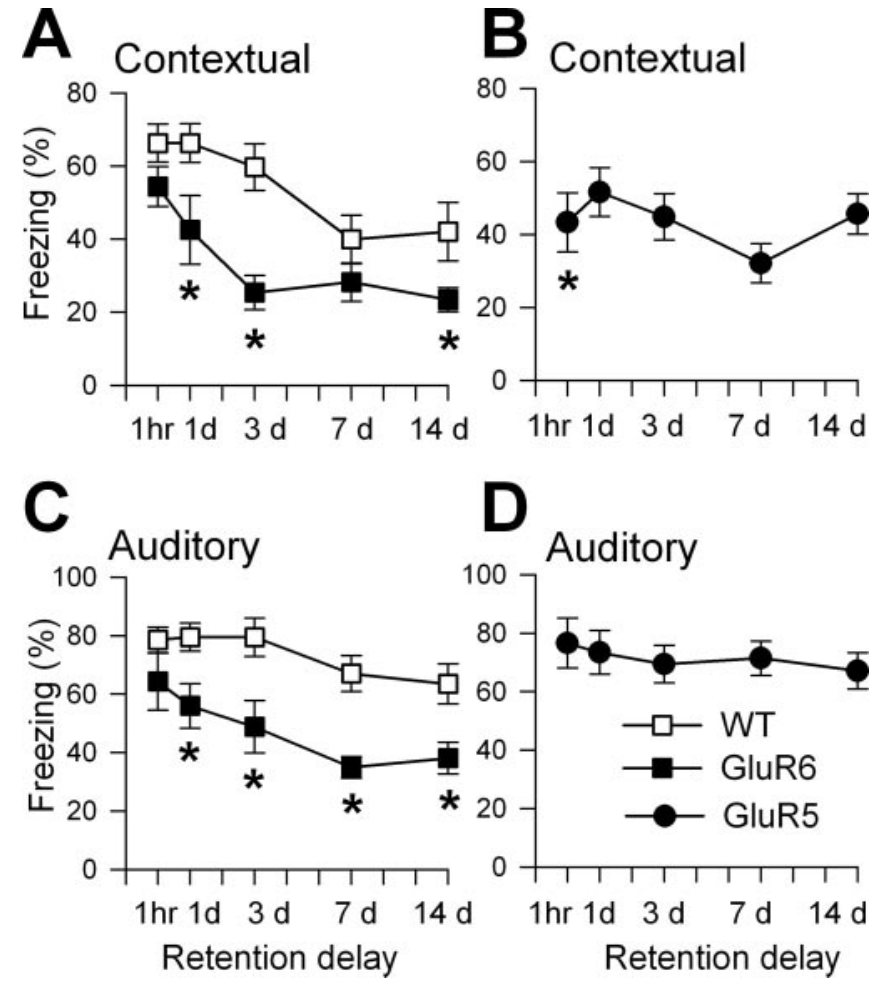

Figure 3. GluR6 but not GluR5 is required for fear memory. $A, B$, Contextual fear conditioning in GluR6 or GluR5 knock-out and wild-type (WT) mice at $1 \mathrm{~h}$ and 1, 3, 7, and $14 \mathrm{~d}$ after training. $C, D$, Auditory fear conditioning in GluR6 or GluR5 knock-out and wild-type mice at $1 \mathrm{~h}$ and 1, 3, 7 , and $14 \mathrm{~d}$ after training. ${ }^{*} p<0.05$, significant difference from wild-type mice.

to a previously non-noxious mechanical stimulus, was similar in wild-type mice $(n=6)$, GluR5 knock-out mice $(n=13)$, and GluR6 knock-out mice $(n=6)$ (Fig. $2 C$ ). We also evaluated hindpaw edema by measuring the hindpaw diameter. A similar degree of inflammation was found in wild-type, GluR5, and GluR6 knock-out mice ( $n=5-6$ for each group) (Fig. $2 D$ ), indicating that peripheral responses to inflammation are likely identical in these mice.

\section{Fear memory after classic conditioning}

To determine whether deletion of GluR5 or GluR6 affected longterm fear memory, we performed fear conditioning in wild-type and knock-out mice (Davis et al., 1997; LeDoux, 2000; Maren, 2001). Contextual and auditory fear memory was measured at $1 \mathrm{~h}$ and at 1, 3, 7, and $14 \mathrm{~d}$ after conditioning (Wei et al., 2002). There was no significant difference in freezing responses immediately after training among wild-type mice $(n=8$ mice; $39.6 \pm 4.1 \%)$, GluR5 knock-out mice ( $n=7 ; 33.3 \pm 6.3 \%)$, and GluR6 knockout mice $(n=8 ; 31.0 \pm 8.5 \%)$, suggesting that the deletion of GluR5 and GluR6 did not cause any developmental defect that would interfere with the shock-induced freezing response. This reinforces our assertion that acute nociceptive thresholds in GluR5 and GluR6 knock-out mice were unaffected by the genetic manipulation. GluR6 knock-out mice showed a significant reduction in both contextual and auditory fear memory at early ( 1 and $3 \mathrm{~d}$ ) as well as later ( 1 and 2 weeks) time points after conditioning (Fig. 3). In contrast, contextual and auditory fear memory was unaltered in GluR5 knock-out mice, except for a small reduction at one early time point ( $1 \mathrm{~h}$ after conditioning) (Fig. 3B).
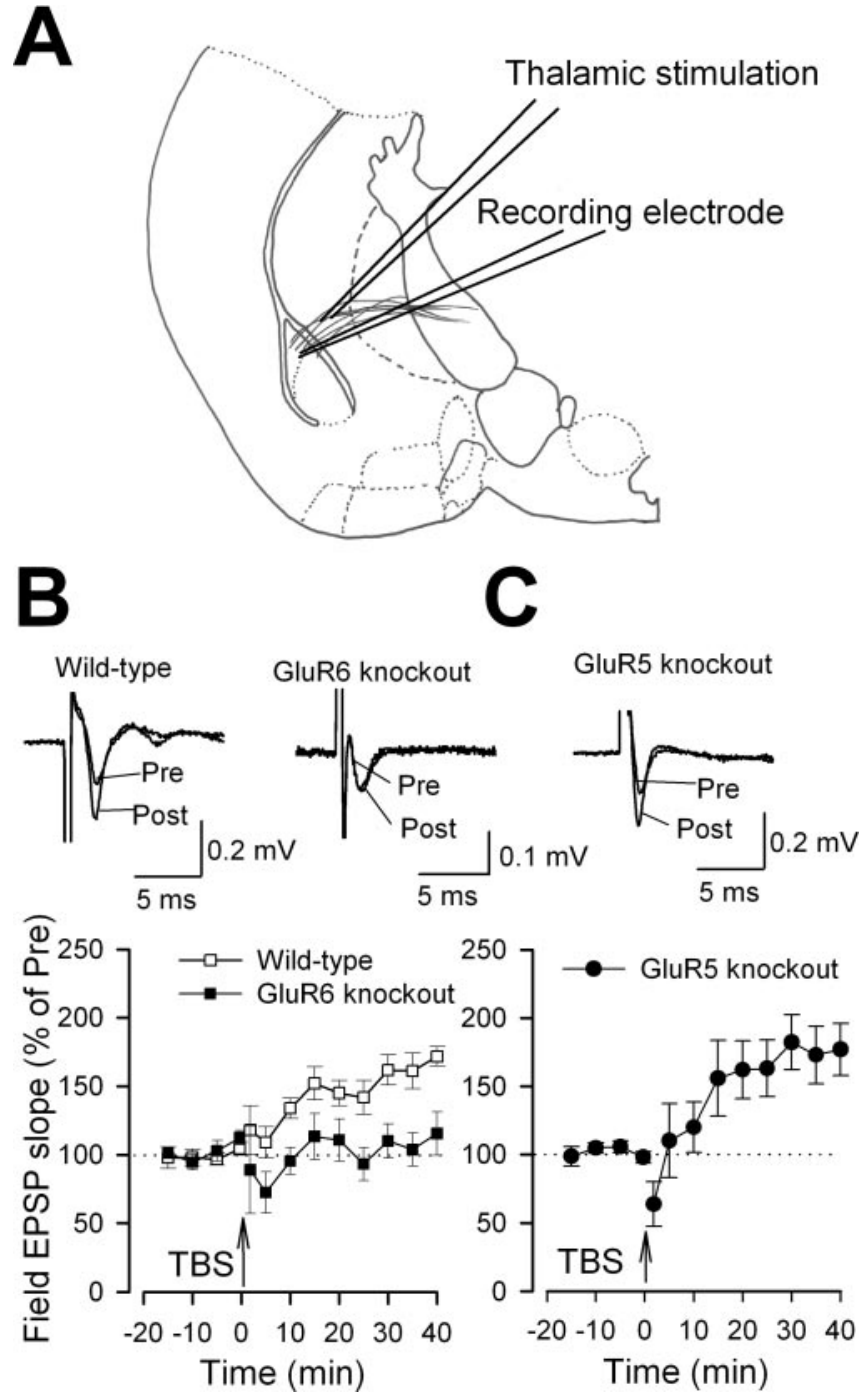

Figure 4. Synaptic potentiation in the amygdala of GluR5 and GluR6 knock-out mice. $A$, Diagram showing the placement of stimulating and recording electrodes in the amygdala. $B, C$, TBS (indicated by the arrow) induced synaptic potentiation in the amygdala of wild-type mice ( $n=11$ slices $/ 9$ mice) and GluR5 knock-out mice ( $n=6$ slices $/ 6$ mice) but not GluR6 knock-out mice ( $n=8$ slices $/ 6$ mice). Inset, Representative records of the fEPSP before (Pre) and $40 \mathrm{~min}$ after (Post) TBS.

KAR-mediated synaptic plasticity in the lateral amygdala Synaptic plasticity, including LTP, is thought to be important for fear learning and memory (Bliss and Collingridge, 1993; McKernan and Shinnick-Gallagher, 1997; Rogan et al., 1997; Maren, 1999; Tsvetkov et al., 2002). Because of the significant reduction of fear memory in GluR6 knock-out mice, we decided to examine synaptic potentiation in the amygdala, a structure known to be important in fear memory. We examined synaptic potentiation at thalamic input synapses to the LA by placing a stimulating electrode in the ventral striatum (Fig. 4A) (Wei et al., 2002). For these experiments, we used five trains of TBS (Frankland et al., 2001; Wei et al., 2002). In wild-type mice, TBS induced significant synaptic potentiation $(164.9 \pm 7.9 \% ; n=11$ slices $/ 9$ mice; $p<$ 0.05 compared with baseline) (Fig. $4 B$ ). However, synaptic potentiation in slices of GluR6 knock-out mice was significantly reduced or blocked $(103.4 \pm 17.2 \% ; n=8$ slices/ 6 mice; $p<0.01$ compared with wild-type mice). In slices of GluR5 knock-out mice $(173.9 \pm 19.7 \% ; n=6$ slices $/ 6$ mice; $p=0.33)$, TBS induced 

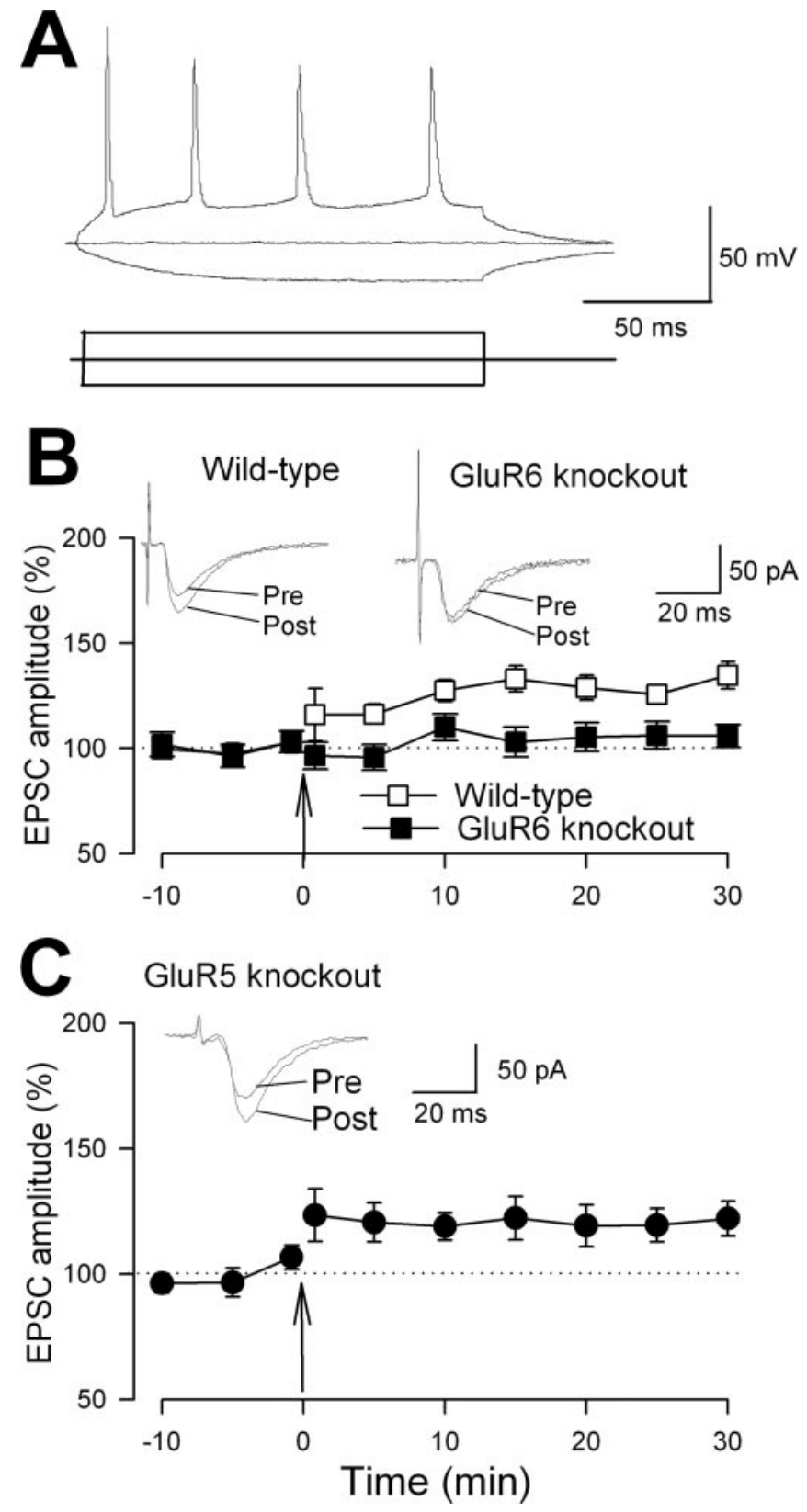

Figure 5. LTP requires the activation of the GluR6 subunit. $A$, Injection of depolarizing current into a neuron induced action potentials that showed significant firing frequency adaptation. $B$, LTP was induced in the LA of wild-type littermates ( $n=9$ slices $/ 5$ mice) but not in GluR6 knock-out mice ( $n=11$ slices $/ 6$ mice). C, Paired training induced LTP in GluR5 knock-out mice ( $n=9$ slices $/ 7$ mice). Inset, Representative records of EPSCs recorded during baseline collection and $20 \mathrm{~min}$ after the pairing training (arrow).

significant synaptic potentiation similar to that of wild-type mice (Fig. 4C).

Next we performed whole-cell patch-clamp recordings from visually identified pyramidal neurons in the LA. Depolarizing currents were injected into the neuron, inducing repetitive action potentials with a frequency adaptation that is typical of the firing pattern of pyramidal neurons (Fig. 5A) (Tsvetkov et al., 2002). EPSCs were recorded in response to stimulation of the thalamic input. LTP was induced by pairing presynaptic stimulation with postsynaptic depolarization (see Materials and Methods). LTP was induced with paired pulses within 15 min after establishing the whole-cell configuration, because it was not possible to in- duce LTP of whole-cell EPSCs in amygdala synapses after 20 min (Tsvetkov et al., 2002). In wild-type littermate mice, the paired training induced long-lasting potentiation of responses $(130.4 \% \pm 6.1 \% ; n=9$ slices $/ 5$ mice; $p<0.05$ compared with baseline) (Fig. $5 B$ ). However, synaptic potentiation in slices of GluR6 knock-out mice was completely blocked (105.4\% $\pm 6.5 \%$; $n=11$ slices $/ 6$ mice; $p<0.05$ compared with wild-type) (Fig. $5 B)$. In slices of GluR5 knock-out mice, the paired training still produced synaptic potentiation $(120.0 \% \pm 3.6 \% ; n=9$ slices $/ 7$ mice; $p=0.17$ compared with wild-type littermates) (Fig. $5 C$ ). The fact that synaptic potentiation was selectively decreased in GluR6 knock-out mice supports results from the fear-memory study and suggests that the GluR6 subunit may play an important role in contextual and auditory fear-memory formation.

\section{KAR-mediated EPSCs in the LA}

What is the mechanism for KAR activation in synaptic potentiation within the amygdala? One possible explanation is that KARs may be located postsynaptically and are activated during training. In rats, it has been reported that KARs contribute to synaptic responses in the amygdala ( $\mathrm{Li}$ et al., 2001; Braga et al., 2003; Rogawski et al., 2003). However, there has not been a similar report in adult mice. To test for possible postsynaptic KARmediated EPSCs, we performed whole-cell patch-clamp recordings from neurons in the LA. Electrical stimulation delivered to the thalamic input (Fig. 4A) induced fast, monosynaptic EPSCs. We blocked NMDA receptors with the selective NMDA receptor inhibitor AP-5 $(50 \mu \mathrm{M})$. The noncompetitive AMPA receptor antagonist SYM2206 (Li et al., 1999) was used to separate potential KAR-mediated EPSCs. SYM2206 was used at $100 \mu \mathrm{M}$, a concentration that produces maximal inhibition of AMPA receptors (half-maximal inhibitory concentration, 1-2 $\mu \mathrm{M}$ ) but $<20-30 \%$ inhibition of KARs (Paternain et al., 1995; Wilding and Huettner, 1995). As shown in Figure $6 A$, bath application of AP-5 plus SYM2206 $(n=17)$ reduced but did not completely block the EPSCs. The residual current was completely blocked by CNQX $(20 \mu \mathrm{M})(n=5)$ (Fig. $6 A, B)$, indicating that the residual current was mediated by KARs. It has been reported that AMPA receptorand KAR-mediated currents have different activation and inactivation kinetics in spinal dorsal horn neurons and hippocampal neurons (Li et al., 1999; Cossart et al., 2002). Our results show that the rise time (10-90\%) and decay time constant $(\tau)$ of KARmediated EPSCs were significantly longer than those of AMPA receptor-mediated currents in LA pyramidal neurons (Fig. $6 C, D)$.

\section{Synaptic potentiation in the auditory cortex}

In addition to the amygdala, the auditory cortex is thought to play a role in the expression of fear memory (LeDoux, 2000). Therefore, we performed similar recordings of LTP in slices of the auditory cortex. In slices of GluR6 knock-out mice, TBS failed to induce significant potentiation $(89.9 \pm 12.1 \% ; n=5$ slices $/ 5$ mice; ) compared with that of wild-type mice (147.0 $\pm 10.0 \%$; $n=7$ slices $/ 7$ mice; $p<0.005$ ) (Fig. $7 B$ ). In slices of GluR5 knock-out mice, however, TBS induced synaptic potentiation $(142.0 \pm 11.2 \% ; n=7$ slices $/ 5$ mice; $p<0.05$ to baseline or GluR6 knock-out mice) (Fig. 7C).

\section{Discussion}

Our results provide evidence for a role of KARs in persistent pain and fear memory. Genetic deletion of GluR5 but not GluR6 significantly reduced responses to capsaicin and formalin, whereas responses to acute thermal or mechanical stimuli were unaf- 


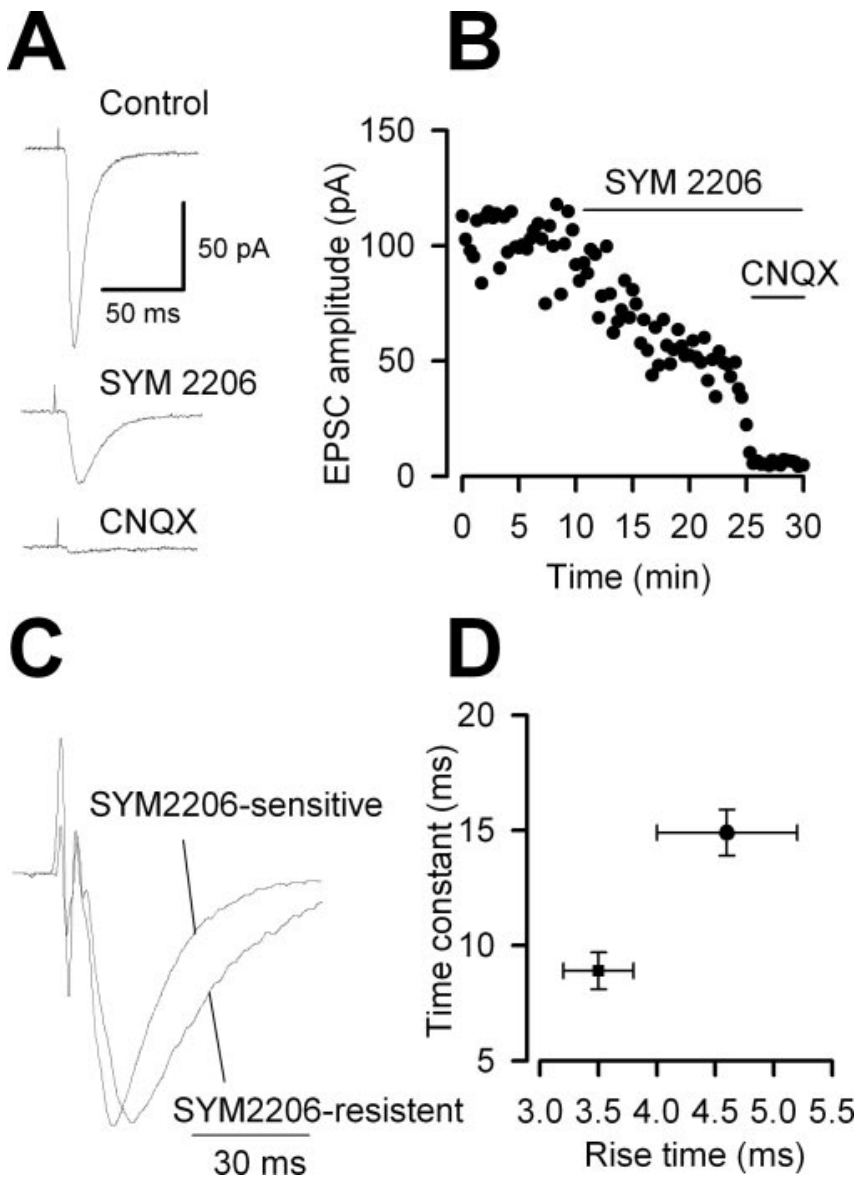

Figure 6. KAR-mediated EPSCs in the LA. A, EPSCs recorded in the presence of AP-5, 5 min after addition of SYM2206 (100 $\mu \mathrm{M})$, and $2 \mathrm{~min}$ after addition of CNQX (20 $\mu \mathrm{M})$ in a LA neuron. $B$, Peak EPSC amplitude versus time for the traces shown in $A$. C, The SYM2206-insensitive EPSC scaled to the peak of the SYM2206-sensitive EPSC. D, Time constant of EPSC decay versus the rising time (10-90\%) for EPSCs mediated by a SYM2206-sensitive (square) and SYM2206insensitive (circle) component.

fected. The involvement of GluR5 receptors is selective, because deletion of GluR6 receptors did not cause any significant change in the same tests for nociceptive behavior. To examine the role of KARs in fear memory induced by painful or noxious stimuli, we also performed classic fear-memory tests. We found that GluR6 but not GluR5 knock-out mice showed a significant reduction in both contextual and auditory fear memory. Electrophysiological evidence showed that LTP induced by TBS or the pairing of synaptic activity with postsynaptic depolarization was blocked in GluR6 knock-out mice. Here we combine the study of fear memory with persistent pain to provide novel evidence for the distinct roles of different KAR subtypes in the central processing of sensory information, from behavioral nociceptive responses to longterm fear memory. Elucidating the unique roles of different receptor subtypes in the transmission of sensory information will further our understanding of how the CNS processes physiological stimuli.

KARs: DRG, spinal cord, and cortical neurons

KARs were first characterized on sensory axons of peripheral nerve fibers (Huettner, 2003). They are abundantly expressed on the small-diameter sensory neurons that form unmyelinated $\mathrm{C}$ fibers, suggesting a potential role for KARs in nociception. Evidence from different approaches indicates that KARs function at
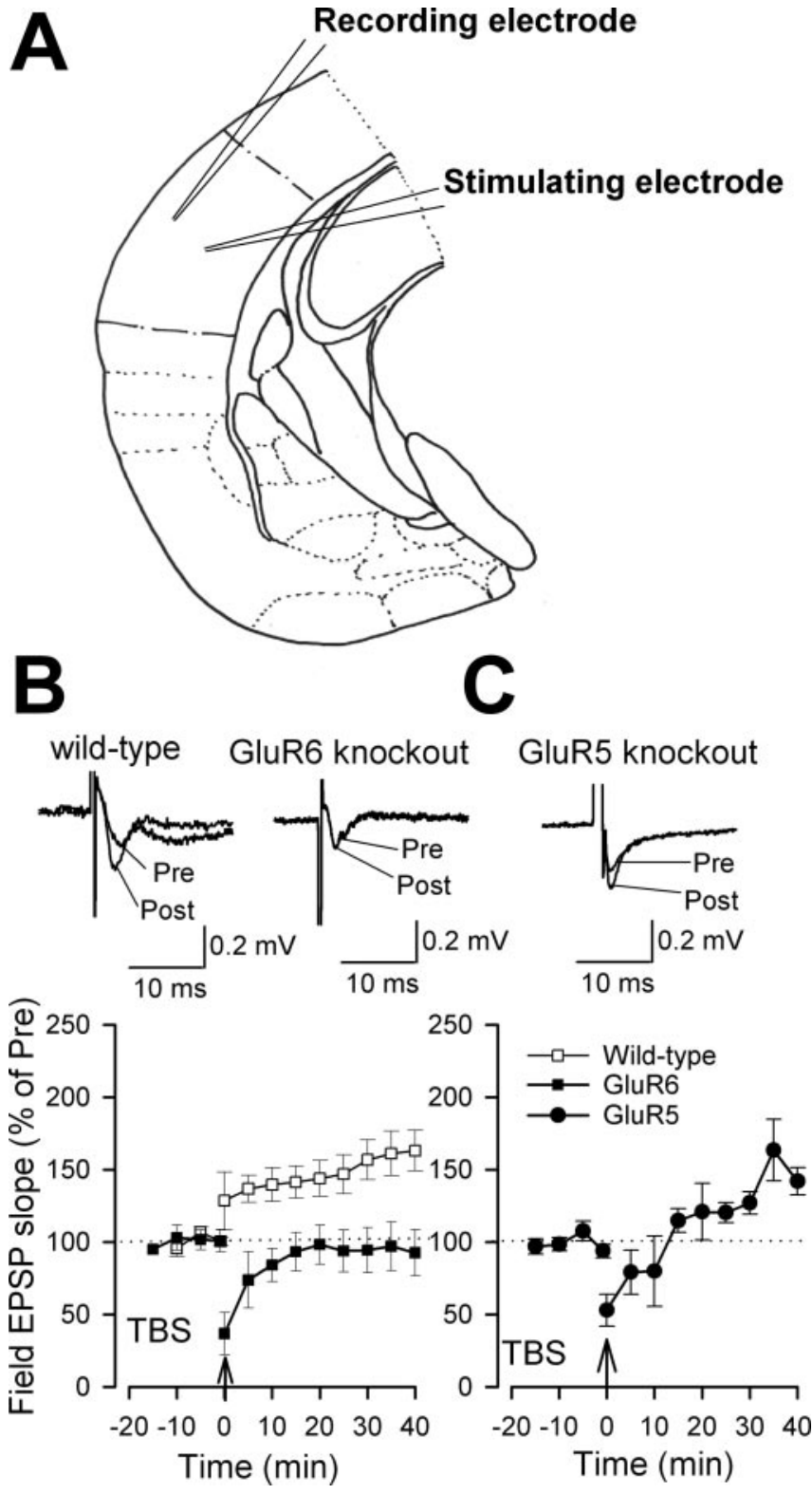

Figure 7. Synaptic potentiation in the auditory cortex of GluR5 and GluR6 knock-out mice. $A$, Diagram showing the placement of stimulating and recording electrodes in the auditory cortex. $B$, C, Deletion of GluR6 and GluR5 affects synaptic potentiation in the auditory cortex. Inset, Representative records of the fEPSP before (Pre) and $40 \mathrm{~min}$ after (Post) TBS. TBS failed to induce significant potentiation in GluR6 knock-out mice ( $n=5$ slices $/ 5$ mice) compared with wild-type mice ( $n=7$ slices $/ 7$ mice) but still induced significant potentiation in GluR5 knockout mice ( $n=7$ slices $/ 5$ mice).

both peripheral and central terminals. At the periphery, KARs can function as sensory receptors to detect glutamate release after injury; at central terminals, KARs act as autoreceptors presynaptically to regulate the release of sensory transmitters (Kerchner et al., 2002). Recent studies using GluR5 and GluR6 knock-out mice showed that functional KARs on DRG cells absolutely require GluR5 (Kerchner et al., 2002). Although recent studies suggest that both GluR5 and GluR6 contribute to KAR-mediated currents in spinal dorsal horn neurons (Kerchner et al., 2002), synaptic responses induced by stimulation of afferent fibers were not significantly affected in GluR5 or GluR6 knock-out mice (Kerchner et al., 2002; Youn and Randic, 2004). These results suggest that other KAR subtypes may contribute to spinal synaptic responses. 


\section{KARs: nociception and inflammatory pain}

Considering the complexity of KARs in spinal sensory transmission and regulation, it is important to evaluate, at the behavioral level, the contribution of KAR subtypes to behavioral responses. For acute responses, we found that the deletion of GluR5 or GluR6 did not affect nociceptive behavior in three different tests. One possible interpretation is that because acute nociceptive responses are important for animals to protect themselves from injury, other postsynaptic receptors, such as AMPA and neuropeptide receptors, may compensate for the loss of postsynaptic KAR-mediated responses. Figure 2 shows that the deletion of GluR5 significantly reduced behavioral responses to formalin injection. The location of GluR5 on DRG cells, along with the reduced phase I response to formalin in GluR5 knock-out mice, suggests that peripheral GluR5 receptors may play a role in early phase I responses. The reduction in phase I may reduce long-term plasticity in the spinal cord and forebrain areas that are important for phase II and III responses. GluR5-containing KARs in supraspinal structures may also contribute to phase II and III responses. Future studies are needed to investigate these possibilities. A similar decrease in nociceptive responses to capsaicin also supports the notion that the contribution of KARs is preferential for long-lasting pain, where the level of synaptic glutamate is likely to be high. The results presented here agree with a previous study that used a selective GluR5 antagonist, LY382884, to show that inhibition of GluR5 activity reduces behavioral responses to formalin (Simmons et al., 1998). Another study showed that mice bearing a targeted mutation at a critical RNA editing site of the GluR5 gene had normal responses to formalin (Sailer et al., 1999). The reason for this discrepancy may be attributable to different levels of functional GluR5 receptors between this transgenic mouse and the ones used here, because the RNA editing mutant retains some functional receptors.

Despite the decrease in nociceptive behaviors seen in the formalin test, mechanical allodynia was not affected in GluR5 knock-out mice in the CFA model. This provides evidence for the dissociation between the nociceptive (licking) response to formalin and the mechanical allodynia observed in the CFA model. Behaviors measured in the formalin test are likely to represent early responses to inflammation, and licking most likely reflects responses to the formalin injection itself. In the CFA model, however, a non-noxious mechanical stimulus was used to induce behavioral withdrawal responses (allodynia). Furthermore, mechanical allodynia in the CFA model usually does not occur until 1-3 d after injury. It is likely that mechanical allodynia in the CFA model involves mostly AMPA receptors in related sensory synapses. Guo et al. (2002) reported that GluR5 mRNA was increased in the spinal cord after CFA injection. Additionally, intrathecal injection of LY382884 decreased thermal hyperalgesia induced by CFA in adult rats, although a high dose of LY382884 produced hindlimb paralysis (Guo et al., 2002). No deficit in locomotor function was detected in GluR5 knock-out mice (our unpublished data). Thus, whether LY382884 also affects spinal motor neurons by acting on GluR5 or produces side effects by acting on other targets remains to be investigated. Our finding that GluR5 knock-out mice show unaltered responses to CFA seems to be in contrast to the report by Guo et al. (2002). However, it should be noted that whereas the present study measured mechanical sensitivity in knock-out mice, Guo et al. (2002) measured thermal sensitivity after acute LY382884 injection intrathecally in rats. These differences may account for this discrepancy. Less information is available about the role of GluR6 in nociception and persistent pain. In the present study, we found that responses to acute noxious stimuli and inflammation were normal in GluR6 knock-out mice, suggesting that the GluR6 subunit is not necessarily required for these behavioral responses. However, these results do not rule out a role for GluR6 in neuronal modulation. Although it has been reported previously that GluR6 mRNA was increased after CFA inflammation (Guo et al., 2002), there is a lack of evidence to show an increase in KAR-mediated currents. We did not see any change in mechanical sensitivity in GluR6 knock-out mice after CFA injection (Fig. 2C). Results from this study suggest that the upregulation of GluR5 and GluR6 mRNA may not reflect a dependency on these subunits for the behavioral responses induced by CFA in GluR5 and GluR6 knock-out mice.

\section{KARs and the amygdala}

KARs contribute to synaptic transmission in the amygdala, a structure important for fear memory (Li and Rogawski, 1998). Li et al. (2001) demonstrated the involvement of KARs in homosynaptic and heterosynaptic potentiation, and results using selective pharmacological agents indicated that GluR5 plays an important role in this plasticity. In the present study, we induced LTP in the lateral amygdala of adult mice using two different standard protocols for LTP: TBS [field EPSP (fEPSP) recording] and the pairing of synaptic activity with postsynaptic depolarization (wholecell patch-clamp recording). We found that the deletion of GluR5 did not affect synaptic potentiation in the amygdala. However, in GluR6 knock-out mice, LTP induced by two different protocols was blocked. The activation of GluR5 KARs was shown to affect inhibitory transmission in the amygdala (Braga et al., 2003). The LTP reported here is likely to be independent of inhibitory transmission, because inhibitory transmission was completely blocked in the whole-cell patch-clamp recordings. Future studies will use KAR knock-out mice to examine the possible regulation of inhibitory transmission within the amygdala in adult animals.

KARs are believed to be important for learning and memory, in part because of their roles in synaptic plasticity in the hippocampus and amygdala (Frerking and Nicoll, 2000; Kullmann, 2001; Huettner et al., 2002; Lerma, 2003). Early contextual and auditory fear memory is mediated by the hippocampus and/or amygdala, whereas late contextual memory may be mediated by cortical areas (Sutherland and McDonald, 1990). Despite in vitro electrophysiological evidence of KARs in the amygdala, little information is available about the roles of KARs in learning and memory. In the present study, we provide evidence that GluR6, but not GluR5, contributes to fear memory. Consistent with behavioral findings, LTP in the amygdala of GluR6 but not GluR5 knock-out mice was significantly reduced. It is unlikely that the defect in fear memory observed in GluR6 knock-out mice is caused by changes in nociception, because responses to acute and inflammatory pain were comparable with that of wild-type mice.

In summary, these results suggest distinct roles for separate KAR subtypes in physiological functions, from persistent pain to fear memory. KARs are shown to contribute to synaptic transmission, regulation, and plasticity in different regions of the CNS (Lerma, 2003). Understanding the contributions of different glutamate receptor subtypes may provide potential new molecular targets for treating diseases such as chronic pain, fear, and memory loss.

\section{References}

Bliss TV, Collingridge GL (1993) A synaptic model of memory: long-term potentiation in the hippocampus. Nature 361:31-39.

Braga MF, Aroniadou-Anderjaska V, Xie J, Li H (2003) Bidirectional mod- 
ulation of GABA release by presynaptic glutamate receptor 5 kainate receptors in the basolateral amygdala. J Neurosci 23:442-452.

Caterina MJ, Leffler A, Malmberg AB, Martin WJ, Trafton J, Petersen-Zeitz KR, Koltzenburg M, Basbaum AI, Julius D (2000) Impaired nociception and pain sensation in mice lacking the capsaicin receptor. Science 288:306-313.

Chaplan SR, Bach FW, Pogrel JW, Chung JM, Yaksh TL (1994) Quantitative assessment of tactile allodynia in the rat paw. J Neurosci Methods 53:55-63.

Cossart R, Epsztein J, Tyzio R, Becq H, Hirsch J, Ben-Ari Y, Crepel V (2002) Quantal release of glutamate generates pure kainate and mixed AMPA/ kainate EPSCs in hippocampal neurons. Neuron 35:147-159.

Davies J, Evans RH, Francis AA, Watkins JC (1979) Excitatory amino acid receptors and synaptic excitation in the mammalian central nervous system. J Physiol (Paris) 75:641-654.

Davis M, Walker DL, Lee Y (1997) Amygdala and bed nucleus of the stria terminalis: differential roles in fear and anxiety measured with the acoustic startle reflex. Philos Trans R Soc Lond B Biol Sci 352:1675-1687.

Frankland PW, O'Brien C, Ohno M, Kirkwood A, Silva AJ (2001) $\alpha$-CaMKII-dependent plasticity in the cortex is required for permanent memory. Nature 411:309-313.

Frerking M, Nicoll RA (2000) Synaptic kainate receptors. Curr Opin Neurobiol 10:342-351.

Guo W, Zou S, Tal M, Ren K (2002) Activation of spinal kainate receptors after inflammation: behavioral hyperalgesia and subunit gene expression. Eur J Pharmacol 452:309-318.

Hollmann M, Heinemann S (1994) Cloned glutamate receptors. Annu Rev Neurosci 17:31-108.

Huettner JE (1990) Glutamate receptor channels in rat DRG neurons: activation by kainate and quisqualate and blockade of desensitization by Con A. Neuron 5:255-266.

Huettner JE (2003) Kainate receptors and synaptic transmission. Prog Neurobiol 70:387-407.

Huettner JE, Kerchner GA, Zhuo M (2002) Glutamate and the presynaptic control of spinal sensory transmission. The Neuroscientist 8:89-92.

Hwang SJ, Pagliardini S, Rustioni A, Valtschanoff JG (2001) Presynaptic kainate receptors in primary afferents to the superficial laminae of the rat spinal cord. J Comp Neurol 436:275-289.

Kerchner GA, Zhuo M (2002) Presynaptic suppression of dorsal horn inhibitory transmission by $\mu$-opioid receptors. J Neurophysiol 88:520 -522 .

Kerchner GA, Wilding TJ, Li P, Zhuo M, Huettner JE (2001a) Presynaptic kainate receptors regulate spinal sensory transmission. J Neurosci 21:59-66.

Kerchner GA, Wang GD, Qiu CS, Huettner JE, Zhuo M (2001b) Direct presynaptic regulation of GABA/glycine release by kainate receptors in the dorsal horn: an ionotropic mechanism. Neuron 32:477-488.

Kerchner GA, Wilding TJ, Huettner JE, Zhuo M (2002) Kainate receptor subunits underlying presynaptic regulation of transmitter release in the dorsal horn. J Neurosci 22:8010-8017.

Kullmann DM (2001) Presynaptic kainate receptors in the hippocampus: slowly emerging from obscurity. Neuron 32:561-564.

LeDoux JE (2000) Emotion circuits in the brain. Annu Rev Neurosci 23:155-184.

Lerma J (2003) Roles and rules of kainate receptors in synaptic transmission. Nat Rev Neurosci 4:481-495.

Li H, Rogawski MA (1998) GluR5 kainate receptor mediated synaptic transmission in rat basolateral amygdala in vitro. Neuropharmacology 37:1279-1286.

Li H, Chen A, Xing G, Wei ML, Rogawski MA (2001) Kainate receptormediated heterosynaptic facilitation in the amygdala. Nat Neurosci 4:612-620.

Li P, Wilding TJ, Kim SJ, Calejesan AA, Huettner JE, Zhuo M (1999)
Kainate-receptor-mediated sensory synaptic transmission in mammalian spinal cord. Nature 397:161-164.

Maren S (1999) Long-term potentiation in the amygdala: a mechanism for emotional learning and memory. Trends Neurosci 22:561-567.

Maren S (2001) Neurobiology of Pavlovian fear conditioning. Annu Rev Neurosci 24:897-931.

McKernan MG, Shinnick-Gallagher P (1997) Fear conditioning induces a lasting potentiation of synaptic currents in vitro. Nature 390:607-611.

Mulle C, Sailer A, Perez-Otano I, Dickinson-Anson H, Castillo PE, Bureau I, Maron C, Gage FH, Mann JR, Bettler B, Heinemann SF (1998) Altered synaptic physiology and reduced susceptibility to kainate-induced seizures in GluR6-deficient mice. Nature 392:601-605.

Mulle C, Sailer A, Swanson GT, Brana C, O'Gorman S, Bettler B, Heinemann SF (2000) Subunit composition of kainate receptors in hippocampal interneurons. Neuron 28:475-484

Partin KM, Patneau DK, Winters CA, Mayer ML, Buonanno A (1993) Selective modulation of desensitization at AMPA versus kainate receptors by cyclothiazide and concanavalin A. Neuron 11:1069-1082.

Paternain AV, Morales M, Lerma J (1995) Selective antagonism of AMPA receptors unmasks kainate receptor-mediated responses in hippocampal neurons. Neuron 14:185-189.

Procter MJ, Houghton AK, Faber ES, Chizh BA, Ornstein PL, Lodge D, Headley PM (1998) Actions of kainate and AMPA selective glutamate receptor ligands on nociceptive processing in the spinal cord. Neuropharmacology 37:1287-1297.

Rogan MT, Staubli UV, LeDoux JE (1997) Fear conditioning induces associative long-term potentiation in the amygdala. Nature 390:604-607.

Rogawski MA, Gryder D, Castaneda D, Yonekawa W, Banks MK, Lia H (2003) GluR5 kainate receptors, seizures, and the amygdala. Ann NY Acad Sci 985:150-162.

Sailer A, Swanson GT, Perez-Otano I, O'Leary L, Malkmus SA, Dyck RH, Dickinson-Anson H, Schiffer HH, Maron C, Yaksh TL, Gage FH, O'Gorman S, Heinemann SF (1999) Generation and analysis of GluR5(Q636R) kainate receptor mutant mice. J Neurosci 19:8757-8764.

Simmons RM, Li DL, Hoo KH, Deverill M, Ornstein PL, Iyengar S (1998) Kainate GluR5 receptor subtype mediates the nociceptive response to formalin in the rat. Neuropharmacology 37:25-36.

Sutherland RJ, McDonald RJ (1990) Hippocampus, amygdala, and memory deficits in rats. Behav Brain Res 37:57-79.

Tolle TR, Berthele A, Zieglgansberger W, Seeburg PH, Wisden W (1993) The differential expression of 16 NMDA and non-NMDA receptor subunits in the rat spinal cord and in periaqueductal gray. J Neurosci 13:5009-5028.

Tsvetkov E, Carlezon WA, Benes FM, Kandel ER, Bolshakov VY (2002) Fear conditioning occludes LTP-induced presynaptic enhancement of synaptic transmission in the cortical pathway to the lateral amygdala. Neuron 34:289-300.

Tsvetkov E, Shin RM, Bolshakov VY (2004) Glutamate uptake determines pathway specificity of long-term potentiation in the neural circuitry of fear conditioning. Neuron 41:139-151.

Wei F, Wang GD, Kerchner GA, Kim SJ, Xu HM, Chen ZF, Zhuo M (2001) Genetic enhancement of inflammatory pain by forebrain NR2B overexpression. Nat Neurosci 4:164-169.

Wei F, Qiu CS, Liauw J, Robinson DA, Ho N, Chatila T, Zhuo M (2002) Calcium calmodulin-dependent protein kinase IV is required for fear memory. Nat Neurosci 5:573-579.

Wilding TJ, Huettner JE (1995) Differential antagonism of $\alpha$-amino-3hydroxy-5-methyl-4-isoxazolepropionic acid-preferring and kainatepreferring receptors by 2,3-benzodiazepines. Mol Pharmacol 47:582-587.

Youn DH, Randic M (2004) Modulation of excitatory synaptic transmission in the spinal substantia gelatinosa of mice deficient in kainate receptor GluR5 or 6 subunit. J Physiol (Lond) 555:683-698. 